Revista Brasileira de Agricultura Irrigada v.13, nº.4, p. 3588 - 3598, 2019

ISSN 1982-7679 (On-line)

Fortaleza, CE, INOVAGRI - http://www.inovagri.org.br

DOI: $10.7127 /$ rbai.v13n4001090

Protocolo 1090.19 - 10/05/2019 Aprovado em 28/07/2019

\title{
PRODUÇÃO DE RABANETE SOB DIFERENTES MANEJOS DE IRRIGAÇÃO
}

Rodrigo Rafael da Silva ${ }^{1}$, Pedro Henrique Máximo de Souza Carvalho ${ }^{2}$, Jamerson Silva e Silva ${ }^{3}$, William Ralf Santos Conta ${ }^{4}$, Sérgio Oliveira Pinto de Queiroz ${ }^{5}$, Fabiana Ferreira dos Santos ${ }^{6}$

\section{RESUMO}

O estresse hídrico ao longo do ciclo da cultura do rabanete pode interferir no seu desenvolvimento através de alterações morfológica, fisiológicas e bioquímicas. O presente trabalho teve como objetivo avaliar o desempenho produtivo de cultivares de rabanete, quando submetidos a diferentes manejos de irrigação. Adotou-se delineamento em blocos casualizados, em esquema de parcelas subdivididas, tendo três manejos de irrigação: Tensiometria, FDR e Tanque classe A nas parcelas e duas cultivares de rabanete: Crimson seleção especial $(\mathrm{C} 1)$ e Crimson gigante $(\mathrm{C} 2)$ nas subparcelas, repetidos cinco vezes. As variáveis analisadas foram: diâmetro e comprimento de raízes, massa fresca e seca da parte aérea, além de teor de sólidos solúveis, $\mathrm{pH}$, acidez titulável e relação sólido solúvel/acidez titulável da raíz. Também foram determinadas a produtividade comercial e a eficiência no uso da água. $\mathrm{O}$ manejo da irrigação baseado na FDR resultou em maior eficiência no uso da água, especialmente se comparado ao manejo baseado no tanque Classe A. A cultivar Crinson gigante apresentou desempenho agronômico superior à Crinson seleção especial.

Palavras-chave: Raphanus sativus, manejo de água, evapotranspiração.

\section{RADISH PRODUCTION UNDER DIFFERENT IRRIGATION MANAGEMENT}

\footnotetext{
ABSTRACT

Water stress throughout the crop cycle of the radish may interfere with its development through morphological, physiological and biochemical changes. The present work had as objective to

${ }^{1}$ Mestrando no Programa de Manejo de Solo e Água, PPMSA/ Universidade Federal Rural do Semi-árido, UFERSA, Campus Mossoró, Rio Grande do Norte, Brasil. E-mail: rodrigosilva_rafael@hotmail.com

2 Graduando em Engenharia Agronômica, Universidade Estadual da Bahia, Juazeiro, Bahia, Brasil. E-mail: pedrocarvalho2008@hotmail.com

Graduando em Engenharia Agronômica, Universidade Estadual da Bahia, Juazeiro, Bahia, Brasil. E-mail: jamersonsilva28@gmail.com

4 Engenheiro Agrônomo formado na Universidade Estadual da Bahia, Juazeiro, Bahia, Brasil. E-mail: ralfw20@gmail.com

${ }^{5}$ Professor e pesquisador na Universidade Estadual da Bahia, Juazeiro, Bahia, Brasil. E-mail: sopqueiroz@gmail.com

6 Graduanda em Engenharia Agronômica, Universidade Estadual da Bahia, Juazeiro, Bahia, Brasil. E-mail: fabianabia_05@hotmail.com
} 
evaluate the productive performance of radish cultivars, submitted to different irrigation management. A randomized complete block design was used, in a subdivided plot scheme, with three irrigation managements: Tensiometry, FDR and class A pan in plots and two cultivars of radish: Crimson special selection $(\mathrm{C} 1)$ and Crimson giant $(\mathrm{C} 2)$ in the subplots, repeated five times. The analyzed variables were: root diameter and length, fresh and dry shoot mass, soluble solids content, $\mathrm{pH}$, titratable acidity and soluble solid / titratable acidity ratio. Commercial productivity and water use efficiency were also determined. FDR-based irrigation management has resulted in greater water use efficiency, especially when compared to Class A tank-based management. The cultivar Crinsom gigante presented superior agronomic performance to the Crinsom special selection.

Keywords: Raphanus sativus, water management, evapotranspiration.

\section{INTRODUÇÃ̃O}

O rabanete (Raphanus sativus L.) pertence à família Brassicaceae, sendo originário da região mediterrânea (RODRIGUES et al., 2013), tendo raiz formada por um bulbo de cor vermelha e sabor picante. Apresenta propriedades medicinais como expectorante natural e estimulante do sistema digestivo, contendo vitaminas A, B1, B2, potássio, cálcio, fósforo e enxofre (OLIVEIRA et al., 2010).

Segundo Cunha et al. (2017), o levantamento realizado pela Embrapa em 2016 revelou que, no Brasil, 800 mil hectares são destinados à produção de olerícolas, nos quais são produzidos 19,3 milhões de toneladas, resultando em produtividade de 24,1 toneladas por hectare. O rabanete é uma hortaliça que vem ganhando destaque entre os olericultores por apresentar características desejáveis como menor ciclo de produção e rusticidade, podendo ser colhido entre 25 e 30 dias após a semeadura. No Brasil apresenta produção crescente (PULITI et al., 2009), sendo cultivada principalmente por pequenos e médios olericultores do cinturão verde dos grandes centros (OLIVEIRA et al., 2010).

O cultivo de hortaliças é considerado exigente no âmbito hídrico, sendo a irrigação fator determinante para a produção agrícola em algumas regiões do Brasil, principalmente na região Nordeste e mais precisamente no semiárido, onde a escassez hídrica é um constante fator causador de variabilidade produtiva. Nesse sentido, a irrigação tem a função de fornecer água em quantidade que evite o estresse hídrico, refletindo-se tanto na qualidade como na produtividade das culturas.

Durante o ciclo da cultura do rabanete, o estresse hídrico pode afetar seu desenvolvimento fisiológico e morfológico, refletindo diretamente na produção final, podendo resultar na isoporização das raízes, imprimindo um aspecto esponjoso e rachaduras ao longo das mesmas (FILGUEIRA, 2008). Desse modo, o uso de técnicas de irrigação surge como alternativa para evitar o decréscimo de produtividade e diminuição dos riscos associados ao cultivo (BERNARDINO et al., 2017). A irrigação, todavia, deve ser adequadamente planejada, permitindo elevada produção final, através da manutenção da umidade do solo próximo à capacidade de campo (AZEVEDO, 2008; BREGONCI et al., 2008), uma vez que a cultura é sensível às flutuações de umidade no solo (LIMA et al., 2015).

A irrigação localizada, em especial o gotejamento, adequa-se ao sistema produtivo do rabanete sob clima semiárido, caracterizando-se por irrigar uma pequena fração da área total, elevar a eficiência de absorção da água pelas plantas, limitando a perda de água por evaporação. Além da escolha do método a ser adotado é imprescindível a adoção de manejo de irrigação, de modo a maximizar a eficiência no uso da água, evitando a ocorrência de estresse associado ao excesso ou escassez de água (CARVALHO et al., 2013), reduzindo o custo de produção, aliando-o à elevação da produção. Dessa forma, o objetivo deste trabalho foi avaliar o desempenho produtivo 


\section{PRODUÇÃO DE RABANETE SOB DIFERENTES MANEJOS DE IRRIGAÇÃO}

de cultivares de rabanete, quando submetidos a diferentes manejos de irrigação.

\section{MATERIAIS E MÉTODOS}

A pesquisa foi conduzida no campo experimental do Departamento de Tecnologia e Ciências Sociais DTCS, da Universidade do Estado da Bahia - UNEB, Juazeiro, Ba (Lat. $09^{\circ} 24^{\prime} 50^{\prime}$ S, Long. $40^{\circ} 30^{\prime} 10^{\prime}$ 'W, alt. 368 $\mathrm{m})$, em uma área de $48 \mathrm{~m}^{2}$. O clima da região de Juazeiro-BA é classificado como BSwh, de acordo com a classificação de Köppen ou seja, clima árido com precipitação anual total média compreendida entre 380 e $760 \mathrm{~mm}$ e temperatura média anual do ar maior que 18 ${ }^{\circ} \mathrm{C}$.
O experimento foi conduzido durante o período de 19 de abril a 21 de maio de 2018, no qual foram avaliadas duas cultivares de rabanete: Crimson seleção especial e Crimson gigante, semeadas diretamente no campo. As análises do solo da área experimental foram realizadas no Laboratório de Análises de Solo, Água e Calcário - LASAC do DTCS/UNEB, que foi classificado como NEOSSOLO FLÚVICO de acordo com o Sistema Brasileiro de Classificação do Solo (EMBRAPA, 2018). Na Tabela 1 estão apresentados os resultados da caracterização química para as profundidades de 0-20 e de 20-40 cm, além de alguns parâmetros físicos, como densidade do solo (Ds) e densidade de partícula (Dp) para o solo utilizado no experimento para a profundidade de $0-20 \mathrm{~cm}$.

Tabela 1. Análise química e física de um NEOSSOLO FLÚVICO cultivado com rabanete entre abril e maio de 2018.

\begin{tabular}{|c|c|c|c|c|c|c|c|c|c|}
\hline Prof. & $\mathrm{Ca}^{+2}$ & $\mathrm{Mg}^{+2}$ & $\mathrm{~K}^{+}$ & $\mathrm{Na}^{+}$ & SB & $\mathrm{Al}^{+3}$ & $\mathrm{P}$ & $\mathrm{pH}$ & C.E \\
\hline$(\mathrm{cm})$ & \multicolumn{6}{|c|}{$\mathrm{cmol}_{\mathrm{c}} \mathrm{dm}^{-3} \mathrm{de}$ TFSA } & $\mathrm{mg} \mathrm{dm}^{-3}$ & $\mathrm{H}_{2} \mathrm{O}$ & $\mathrm{dS} \mathrm{m}^{-1}$ \\
\hline $0-20$ & 4,00 & 2,50 & 0,57 & 0,06 & 7,13 & 0,05 & 62,00 & 6,24 & 1,55 \\
\hline $20-40$ & 5,00 & 1,50 & 0,33 & 0,05 & 6,88 & 0,05 & 54,00 & 6,56 & 1,12 \\
\hline \multicolumn{2}{|c|}{ Prof } & \multicolumn{4}{|c|}{ Densidade do solo (Ds) } & \multicolumn{4}{|c|}{ Densidade de partícula (Dp) } \\
\hline \multicolumn{2}{|c|}{$(0-20 \mathrm{~cm})$} & \multicolumn{4}{|c|}{$1,42 \mathrm{~g} \mathrm{~cm}^{-3}$} & \multicolumn{4}{|c|}{$2,4 \mathrm{~g} \mathrm{~cm}^{-3}$} \\
\hline
\end{tabular}

Prof. - Profundidade. Cálcio $\left(\mathrm{Ca}^{+2},\right)$ magnésio $\left(\mathrm{Mg}^{+2}\right)$, potássio $\left(\mathrm{K}^{+2}\right)$, sódio $\left(\mathrm{Na}^{+}\right)$e alumínio tocável $\left(\mathrm{Al}^{+3}\right)$, soma de base $(\mathrm{SB})$, fosforo $(\mathrm{P})$, potencial de hidrogênio $(\mathrm{pH})$ e condutividade elétrica (C.E).

O preparo da área consistiu-se em uma aração e gradagem, associadas à construção de canteiros com aproximadamente $0,40 \mathrm{~m}$ de largura e 0,20 $\mathrm{m}$ de altura, distribuindo-se uma fita gotejadora por canteiro em todas as parcelas, com espaçamento entre gotejadores de $0,20 \mathrm{~m}$ e vazão nominal de $2,4 \mathrm{~L} \mathrm{~h}^{-1}$, sob pressão de serviço de $100 \mathrm{kPa}$. Após a instalação foi realizado o teste de uniformidade de distribuição de água através da metodologia proposta por proposta por Karmeli e Keller (1975), determinando-se coeficiente de uniformidade de distribuição de água (CUD) de 95\%, posteriormente utilizado para determinação da lâmina diária de reposição de água.

O plantio foi realizado diretamente no local definitivo, sendo colocadas aproximadamente 10 sementes por berço, sob espaçamento entre plantas de $0,2 \mathrm{~m}$ e $1,0 \mathrm{~m}$ entre linhas. Após a germinação ocorreu o desbaste, deixando-se 30 plantas por parcela.

Adotou-se delineamento experimental em blocos casualizados, em esquema de parcelas subdivididas, tendo três manejos de irrigação (Tensiometria, Reflectometria no domínio da frequência - FDR e Tanque classe A) nas parcelas, e duas cultivares de rabanete (Crimson seleção especial - C1 e Crimson gigante - C2) nas subparcelas e cinco blocos composto por seis plantas. O solo apresentava $\theta$ cc de $0,126 \mathrm{~cm}^{3} \mathrm{~cm}^{3}$, o manejo da irrigação por tensiometria e FDR foi realizado com base na curva característica de retenção de água no solo (Figura 1A) repondo a umidade do solo para capacidade de campo, sendo que, para a adoção da FDR, utilizou-se equipamento marca Falker, modelo Hidrofarm I, adotando- 
se ajuste de leitura por curvas de calibração e de retenção de água no solo, apresentadas na

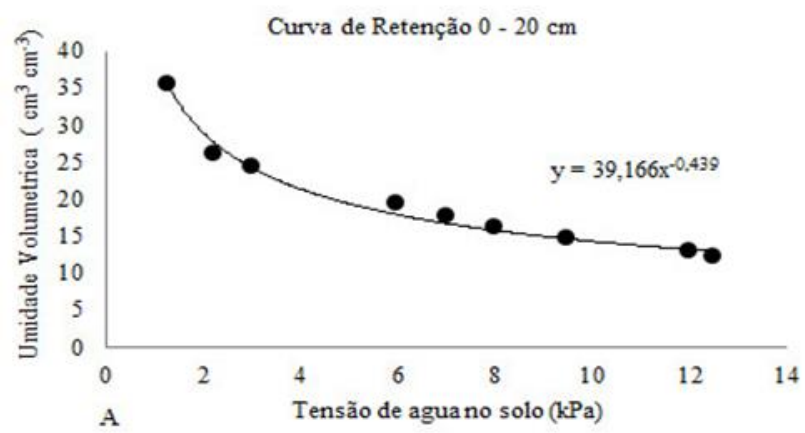

figura $1 \mathrm{~B}$.

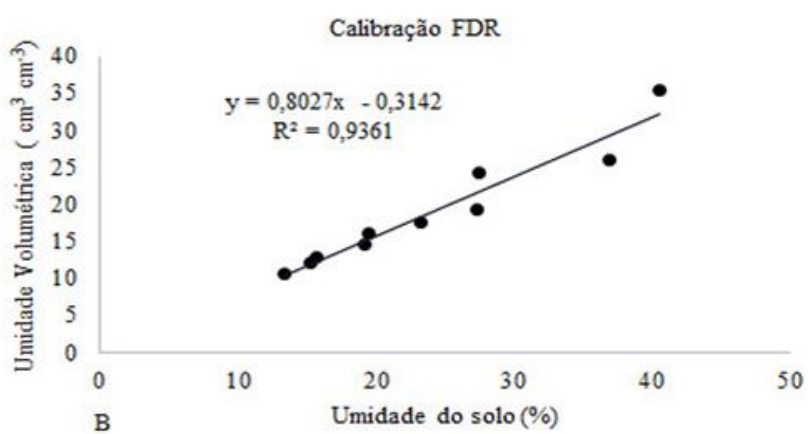

Figura 1. Caracterização hídrica de um NEOSSOLO FLÚVICO cultivado com rabanete: A) curva de retenção de água no solo $0-20 \mathrm{~cm}$; B) curva de calibração da Reflectometria no domínio da frequência - FDR.

Para o tanque classe $\mathrm{A}$, os valores da evaporação foram obtidos da estação meteorológica do DTCS/UNEB, mediante leitura diária, convertida com a multiplicação da ECA pelo coeficiente de tanque (Kp) para evapotranspiração de referencia (ETo), pela

$$
E T c=K p \times E C A \times K c \text {, }
$$

Em que:

ETc - evapotranspiração da cultura $(\mathrm{mm})$;

Kp - coeficiente de tanque;

ECA - evaporação do tanque Classe A (mm);

Kc - coeficiente de cultura.

A colheita foi realizada 31 dias após o plantio e as plantas de cada unidade experimental foram colhidas, separadas e identificadas. Em seguida foram levadas para o laboratório de Olericultura para analisar diâmetro das raízes (DR) e comprimento de raízes $(\mathrm{CR})$, mensurados com auxílio de um paquímetro digital. Para a massa fresca (MFPA) e massa seca da parte aérea (MSPA) utilizou-se balança de precisão. Para a determinação (MSPA), as plantas foram acondicionadas em sacos de papel e postas para secar em estufa a uma temperatura de 70 ${ }^{\circ} \mathrm{C}$ por 72 horas. As análises químicas foram: sólido solúvel (SS), obtida através de 1 gota do extrato aquoso das raízes e determinada com auxílio do refratômetro manual, sendo os resultados expressos em ${ }^{\circ}$ Brix. O potencial de hidrogênio $(\mathrm{pH})$ foi realizado através do extrato aquoso das raízes de rabanete, com auxílio de um peagâmetro digital. A acidez equação 1 e corrigida para evapotranspiração da cultura (ETc) através do coeficiente de cultura (Kc) para cada estádio fenológico, I0,60 , II-0,65, III-0,90 e IV-0,85, como apresentado por Allen et al. (2006).

titulável (AT) foi determinada através da titulação com $\mathrm{NaOH} 0,1 \mathrm{~mol} \mathrm{~L}^{-1}$, utilizando extrato aquoso do rabanete $(10 \mathrm{~mL})$, adicionado a $50 \mathrm{~mL}$ de água destilada e acrescentadas 3 gotas do indicador fenolftaleína. Também foram determinadas a relação sólido solúvel, a acidez titulável (SS/AT), a produtividade comercial $\left(\mathrm{Mg} \mathrm{ha}^{-1}\right)$ e a eficiência de uso da água (EUA). A EUA foi calculada pela razão entre a produtividade total de raízes e o volume de água utilizado no ciclo do rabanete.

Os dados foram submetidos à análise de variância pelo teste $\mathrm{F}(\mathrm{p}<0,05)$ e quando observado efeito significativo aplicado o teste de comparação de médias dos tratamentos entre si pelo teste de Tukey a $5 \%$ de significância, com o auxílio do software estatístico ASSISTAT versão 7.7.

\section{RESULTADOS E DISCUSSÃO}

A densidade do solo é um elemento importante para o melhor desenvolvimento da cultura do rabanete, influenciando a porosidade total e, consequentemente, a 


\section{PRODUÇÃO DE RABANETE SOB DIFERENTES MANEJOS DE IRRIGAÇÃO}

capacidade de armazenamento de água do solo. O valor determinado para o solo do presente experimento foi de $1,42 \mathrm{~g} \mathrm{~cm}^{-3}$, considerado favorável ao desenvolvimento da cultura do rabanete, como pode ser observado na tabela 1. É possível notar que o valor da condutividade elétrica, determinado no extrato de saturação do solo $\left(\mathrm{CE}_{\mathrm{es}}\right)$, não afeta $\mathrm{o}$ desenvolvimento da cultura e que, para Rebequi et al. (2009), os valores de $\left(\mathrm{CE}_{\mathrm{es}}\right)$ quando em altas concentrações são responsáveis por inibir o crescimento e desenvolvimento de grande parte das espécies agrícolas cultivadas, afetando negativamente a produção de massa seca de raízes, bem como a área foliar da planta, ocasionando perda de produtividade (OLIVEIRA et al., 2010), tendo limiar salino em $1,2 \mathrm{dS} \mathrm{m}^{-1}$ no extrato de saturação e $0,8 \mathrm{dS} \mathrm{m} \mathrm{m}^{-1}$ na água de irrigação (AYERS; WESTCOT, 1999), limites superiores aos encontrados no presente experimento.

As condições meteorológicas observadas durante a condução do experimento estão apresentadas na figura 2 . Nesse período, a temperatura diária média do ar foi de $26,1{ }^{\circ} \mathrm{C}$, mínimas variaram de $19,4{ }^{\circ} \mathrm{C}$ a $23,3{ }^{\circ} \mathrm{C}$ e as máximas de 30,1 a $33,7^{\circ} \mathrm{C}$, valores adequados ao melhor desenvolvimento da cultura, conforme Minami e Tessarioli Netto (1997), estando à faixa ideal entre 7,2 e $32,2^{\circ} \mathrm{C}$, sendo a média de $29,4{ }^{\circ} \mathrm{C}$ e máxima de $35^{\circ} \mathrm{C}$.

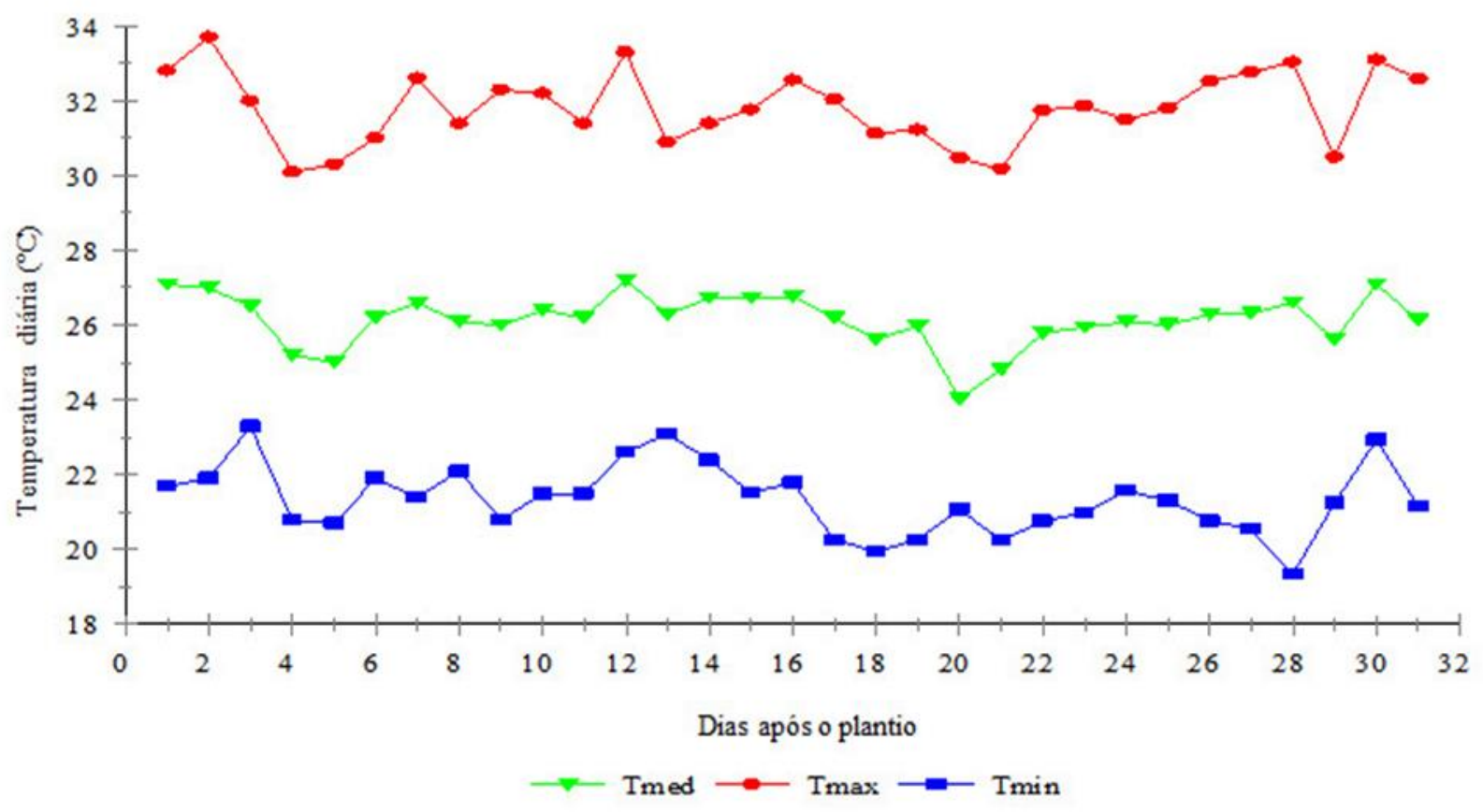

Figura 2. Temperatura média (Tmed), máxima (Tmax) e mínima (Tmin) diária, durante o período experimental de 19 de abril a 21 de maio de 2018.

Os valores de umidade relativa e temperaturas elevadas favorecem 0 desenvolvimento de doenças fúngicas na folhagem da cultura, porém tal fato não foi observado. Ocorreu apenas uma precipitação pluviométrica de $8,3 \mathrm{~mm}$ durante todo $\mathrm{o}$ período de experimento.

A temperatura e umidade relativa do ar são elementos climáticos importantes no desenvolvimento e na produtividade de culturas de ciclo curto, como o rabanete. De acordo com Bonela et al. (2017), o cultivo com elevadas temperaturas e com precipitação favorece o aumento na incidência de doenças foliares, diminuindo a área fotossintética da planta.

As lâminas de irrigação aplicadas em função dos manejos de irrigação estão apresentadas na Figura 3. No manejo com tensiometria e FDR utilizou-se uma lâmina de 44,0 e $42,5 \mathrm{~mm}$, respectivamente, ambos os manejos baseados no solo, enquanto a 
reposição da lâmina de irrigação baseada nos resultados da evaporação do Tanque classe A resultou numa lâmina total aplicada de 69,32 $\mathrm{mm}$, durante o ciclo, superior aos demais manejos empregados. A maior lâmina aplicada está relacionada a uma maior demanda evaporativa e interferências externas, contribuindo para maior lâmina aplicada, o que demonstra a necessidade da obtenção de coeficientes de cultivo específicos para a produção do rabanete em condições climáticas de semiárido. Todavia, tal lâmina foi inferior àquela determinada por Marques e Santos (2005), estudando o efeito de níveis de irrigação na cultura do rabanete cultivar Crimson gigante e utilizando o tanque classe A, estabelecida em $137,0 \mathrm{~mm}$ para $100 \%$ da ECA, no município de Presidente Prudente, SP.

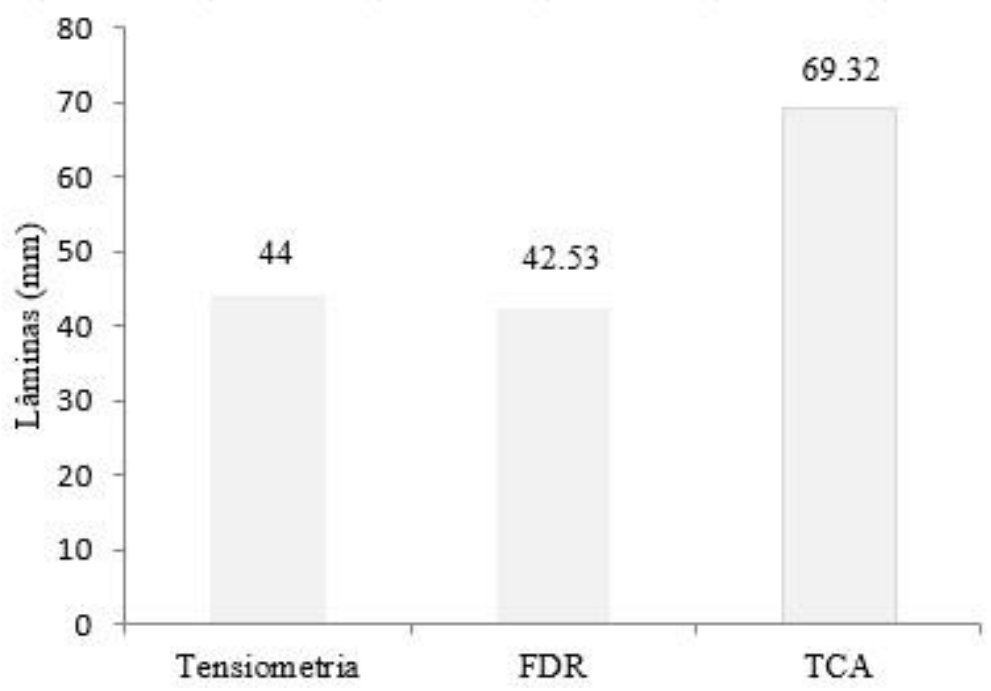

Figura 3. Lâminas de irrigação acumuladas referentes aos manejos de irrigação, Tensiometria, Reflectometria no domínio da frequência (FDR) e Tanque classe A (TCA) durante o cultivo de rabanete em um NEOSSOLO FLÚVICO.

Houve efeito significativo da interação $(\mathrm{p}<0,05)$ para sólido solúvel total e acidez titulável. Para os fatores isolados entre as cultivares todas as variáveis analisadas foram significativas e para os manejos de irrigação apenas EUA.

Na Tabela 2 observa-se o desdobramento da interação dos manejos de irrigação com as cultivares para as variáveis sólido solúvel e acidez titulável. A utilização dos manejos de irrigação por Reflectometria no domínio da frequência (FDR) e Tensiometria, para cultivar Crimson seleção especial (C1) resulta em comportamento semelhante estatisticamente entre si, porém superior àquele observado para o manejo através do Tanque classe A (TCA). 


\section{PRODUÇÃO DE RABANETE SOB DIFERENTES MANEJOS DE IRRIGAÇÃO}

Tabela 2. Desdobramento da interação entre os fatores manejos de irrigação, Tensiometria, Reflectometria no domínio da frequência (FDR) e Tanque classe A (TCA) x cultivares de rabanetes, para a variável de sólido solúvel total (SS) e acidez titulável (AT) cultivados em um NEOSSOLO FLÚVICO.

\begin{tabular}{|c|c|c|c|c|}
\hline \multirow{3}{*}{ Manejos } & \multicolumn{2}{|c|}{ SS } & \multicolumn{2}{|c|}{ AT } \\
\hline & \multicolumn{4}{|c|}{ Cultivares } \\
\hline & $\mathrm{C} 1$ & $\mathrm{C} 2$ & $\mathrm{C} 1$ & $\mathrm{C} 2$ \\
\hline Tensiometria & $3,86 \mathrm{abB}$ & $5,12 \mathrm{aA}$ & $0,14 \mathrm{aA}$ & $0,16 \mathrm{aA}$ \\
\hline FDR & $4,24 \mathrm{aA}$ & $4,64 \mathrm{aA}$ & $0,15 \mathrm{aA}$ & $0,12 \mathrm{Bb}$ \\
\hline TCA & $3,46 \mathrm{bB}$ & $4,78 \mathrm{aA}$ & $0,13 \mathrm{aA}$ & $0,14 \mathrm{abA}$ \\
\hline
\end{tabular}

Médias seguidas de mesma letra minúsculas na coluna e maiúsculas na linha não diferem estatisticamente entre si, pelo teste de Tukey ao nível de 5\% de significância, crimson seleção especial (C1), crimson gigante (C2).

Para as características de sólido solúvel, a similaridade entre esses manejos está relacionada a uma menor lâmina aplicada e consequentemente uma maior concentração dos sólidos. Para cultivar Crimson gigante (C2) não se observou diferença para os tratamentos impostos. Em relação à acidez titulável, os manejos por tensiometria e TCA resultaram em desempenho semelhante entre si, porém diferente daquele obtido ao se adotar manejo por FDR, como resultado esperado pela menor lâmina de reposição de água. Granada et al. (2001) afirmam que valores de Brix e acidez titulável podem sofrer influência da fisiologia da planta, manejo, estação e local de cultivo. Os resultados observados no trabalho corroboram com os citados na literatura, contudo, tais características são mais fortemente influenciadas pela genética e condições de manejos a que as plantas são submetidas.

Os resultados obtidos no presente trabalho foram semelhantes aos encontrados por Cunha et al. (2017), que não observaram diferenças significativas, em função das épocas de cultivo no período de seca e por Santos et al. (2014), estudando o crescimento do rabanete sob diferentes lâminas de irrigação, que verificaram melhor desempenho produtivo sob lâmina de irrigação em $100 \%$ da evapotranspiração de cultivo, inclusive semelhantes às lâminas obtidas no presente experimento.

Não se verificou diferença significativa entre os manejos utilizados para o comprimento de raiz, que variou entre 7,64 e $8,28 \mathrm{~cm}$ para os manejos TCA e FDR, respectivamente (Tabela 3 ). Tal resultado também foi verificado por Bregonci et al. (2008), que submeteram a cultura do rabanete ao déficit hídrico em diferentes fases de seu ciclo e relataram que a lâmina aplicada não afeta o comprimento de raiz. 
Tabela 3. Médias dos fatores insolados do manejo da irrigação Tensiometria, Reflectometria no domínio da frequência (FDR) e Tanque classe A (TCA) e das cultivares de rabanete para as variáveis de diâmetro de raiz (DR), comprimento de raiz (CR), massa fresca da parte aérea (MFPA), massa seca da parte aérea (MSPA), potencial de hidrogênio $(\mathrm{pH})$, relação sólido solúvel total/ acidez titulável (SS/AT), produtividade comercial (PROD) e eficiência no uso da água (EUA) cultivados em um NEOSSOLO FLÚVICO, entre abril e maio de 2018.

\begin{tabular}{ccccccccc}
\hline Manejos & $\begin{array}{c}\text { DR } \\
(\mathrm{cm})\end{array}$ & $\begin{array}{c}\text { CR } \\
(\mathrm{cm})\end{array}$ & $\begin{array}{c}\text { MFPA } \\
(\mathrm{g})\end{array}$ & $\begin{array}{c}\text { MSPA } \\
(\mathrm{g})\end{array}$ & $\mathrm{pH}$ & SS/AT & $\begin{array}{c}\text { PROD } \\
\left(\mathrm{Mg} \mathrm{ha}^{-1}\right)\end{array}$ & $\begin{array}{c}\text { EUA } \\
\left(\mathrm{kg} \mathrm{ha}^{-1} \mathrm{~mm}^{-1}\right)\end{array}$ \\
\hline Tens. & $4,68 \mathrm{a}$ & $7,98 \mathrm{a}$ & $64,32 \mathrm{a}$ & $6,13 \mathrm{a}$ & $7,39 \mathrm{a}$ & $30,14 \mathrm{a}$ & $1,00 \mathrm{a}$ & $0,023 \mathrm{ab}$ \\
FDR & $4,88 \mathrm{a}$ & $8,28 \mathrm{a}$ & $79,88 \mathrm{a}$ & $6,92 \mathrm{a}$ & $7,40 \mathrm{a}$ & $35,34 \mathrm{a}$ & $1,21 \mathrm{a}$ & $0,028 \mathrm{a}$ \\
TCA & $4,88 \mathrm{a}$ & $7,64 \mathrm{a}$ & $60,38 \mathrm{a}$ & $7,00 \mathrm{a}$ & $7,44 \mathrm{a}$ & $31,09 \mathrm{a}$ & $1,16 \mathrm{a}$ & $0,017 \mathrm{~b}$ \\
\hline CV $(\%)$ & 13,41 & 12,4 & 42,51 & 54,24 & 1,5 & 21,11 & 30,11 & 28,69 \\
\hline \multirow{2}{*}{ Cultivares } & DR & CR & MFF & MSF & pH & SS/AT & $\begin{array}{c}\text { PROD } \\
\left(\mathrm{Mg} \mathrm{ha}^{-1}\right)\end{array}$ & $\begin{array}{c}\mathrm{EUA}^{-1} \\
\left(\mathrm{~kg} \mathrm{ha}^{-1}\right)\end{array}$ \\
\hline C1 & $4,53 \mathrm{~b}$ & $6,56 \mathrm{~b}$ & $54,02 \mathrm{~b}$ & $8,21 \mathrm{a}$ & $7,33 \mathrm{~b}$ & $27,92 \mathrm{~b}$ & $0,83 \mathrm{~b}$ & $0,017 \mathrm{~b}$ \\
$\mathrm{C} 2$ & $5,12 \mathrm{a}$ & $9,37 \mathrm{a}$ & $82,36 \mathrm{a}$ & $5,16 \mathrm{~b}$ & $7,49 \mathrm{a}$ & $36,46 \mathrm{a}$ & $1,16 \mathrm{a}$ & $0,029 \mathrm{a}$ \\
\hline CV $(\%)$ & 11,82 & 14,01 & 20,74 & 39,41 & 1,06 & 22,23 & 27,15 & 28,68 \\
\hline As
\end{tabular}

As médias seguidas pela mesma letra não diferem estatisticamente entre si. Foi aplicado o Teste de Tukey ao nível de 5\% de probabilidade. Tens. - Tensiometria; Crimson seleção especial (C1), Crimson gigante (C2).

A matéria fresca e seca da parte aérea não foi influenciada significativamente pelos manejos empregados. Essa maior massa fresca contribui para uma maior área para fotossíntese e consequentemente maior fornecimento de fotoassimilados para a cultura, resultando numa maior possibilidade de crescimento das raízes. Os resultados encontrados nesse trabalho foram superiores àqueles encontrados por Rodrigues et al. (2013) para matéria fresca. Silva et al. (2012) relatam que a massa fresca ou seca de parte aérea apresentam pouca sensibilidade ao nível de água no solo, desde que próximos à capacidade de campo, com o que corroboram Costa et al. (2008), trabalhando com a cultura da beterraba.

Para as variáveis $\mathrm{pH}$, SS/AT e produtividade, não se observaram diferenças de desempenho produtivo, como pode ser visto na Tabela 3. Em função das lâminas de irrigação aplicadas, verificou-se diferença significativa para a eficiência no uso da água entre os diferentes manejos de irrigação, tendo a tensiometria e a FDR resultados semelhantes entre si, porém FDR foi significativamente superior àqueles obtidos com da adoção do TCA. Segundo Slomp et al. (2011), os dados relativos à eficiência do uso de água (EUA), revelam quando o aumento das lâminas de irrigação não consegue produzir aumento de produtividade significativa. A maior eficiência determinada resulta, portanto, da menor lâmina estimada pelo uso da técnica da FDR, quando comparada àquela obtida pelo uso do TCA. Todas as variáveis citadas anteriormente não foram influenciadas pelas diferenças na lâmina de irrigação aplicadas, desde que mantidas condições de umidade do solo próximas à capacidade de campo, o que também foi observado por diversos autores (PEREIRA et al., 1999; BOKHTIAR et al., 2001; BREGONCI et al., 2008; SANTOS et al., 2014).

A cultivar Crimson gigante (C2) apresentou os maiores valores de diâmetro de raiz, comprimento de raiz, matéria fresca da parte aérea, pH, SS/AT, PROD e EUA, quando comparada à cultivar Crimson seleção especial (C1), exceto para matéria seca da parte aérea, como pode ser observado na tabela 3. O diâmetro de raiz da $\mathrm{C} 2$ apresentouse superior ao da cultivar $\mathrm{C} 1$ e tal fato pode estar relacionado às características genéticas da cultivar. Os valores de desempenho produtivo, determinados nesse trabalho para 
cultivar C1, também foram observados por Guerra et al. (2017), para as condições de cultivo na Amazônia. Gadum et al. (2005), cultivando rabanete, não observaram diferença no diâmetro de raiz das cultivares Sparkler e Saxa, em concordância com Faria et al. (2013). O comprimento de raiz significativamente maior em relação à cultivar Crimsom seleção especial (C1) é característico da cultivar Crimson gigante. Cunha et al. (2017) encontrou valores inferiores para comprimento de raiz das cultivares Cometa, Saxa e Sparkler, sob cultivo em época seca do ano. Para massa fresca da folha, houve uma diferença significativa para $\mathrm{C} 2$ em relação a $\mathrm{C} 1$, já para massa seca ocorreu o inverso. $\mathrm{O}$ resultado encontrado nesse trabalho difere do obtido por Bonela et al. (2017), estudando as cultivares Red Jewel e $\mathrm{N}^{\circ} 25$, cv. Vip Crimson, onde não foi observado efeito significativo para tais variáveis.

Os valores de $\mathrm{pH}, \mathrm{SS} / \mathrm{AT}$, produtividade e EUA, foram significativamente superiores para a cultivar $\mathrm{C} 2$, estando relacionadas à genética da cultivar.

A produtividade para cultivar Crimson gigante (C2) apresentou-se superior àquela obtida pela cultivar Crimson seleção especial, determinando-se 1,16 e $0,83 \mathrm{Mg} \mathrm{ha}^{-1}$. Os valores encontrados no presente experimento são inferiores àqueles obtidos em outros experimentos, em função do espaçamento utilizado ser superior ao recomendado na literatura, devendo-se tal fato à necessidade de isolar os efeitos da umidade do solo, proveniente dos diferentes manejos de irrigação adotados, evitando o encontro de bulbos úmidos. O espaçamento tem reflexo direto na baixa produtividade, como observado no presente experimento. Para a EUA, a cultivar $\mathrm{C} 2$ apresentou uma maior produtividade com uma menor lâmina utilizada na produção, quando comparada a cultivar $\mathrm{C} 1$.

\section{CONCLUSÕES}

O manejo da irrigação baseado na FDR resultou em maior eficiência no uso da água, especialmente se comparado ao manejo baseado no tanque Classe A.

A cultivar Crimson gigante apresentou desempenho agronômico superior à Crimson seleção especial.

\section{REFERÊNCIAS BIBLIOGRÁFICAS}

ALLEN, R. G.; PEREIRA, L. S.; RAES, D.; SMITH, M. Evaporación del cultivo. Guías para la determinación de los requerimientos de agua de los cultivos. Roma: FAO, 2006. 298 p. (/Estudio FAO. Riego y Drenage, 56).

AYERS, R. S.; WESTCOT, D. W. A qualidade da água na agricultura. Tradução de H. R. GHEYI, J. F. DE MEDEIROS E F. A. V. DAMASCENO. 2. ed. Campina Grande: UFPB, 1999. 153 p. (Estudos FAO. Irrigação e Drenagem, 29).

AZEVEDO, L. P. de. Uso de dois espaçamentos entre gotejadores na mesma linha lateral e seus efeitos sobre a formação do bulbo molhado, produtividade $\mathrm{e}$ qualidade de rabanete (Raphanus sativus L.). 2008. 76 f. Tese (Doutorado em Irrigação e Drenagem) Universidade Estadual Paulista, Botucatu.

BERNADO, S.; SOARES, A. A.; MANTOVANI, E. C. Manual de irrigação. 7. ed. Viçosa, MG: UFV, 2005. 611p.

BERNARDINO, M. M.; ALVES, D. M.; DIAS, J, H. R.; BASTOS, A. V. S.; SANTOS, L. N. S. dos; COSTA, C. T. S. Cultivo do rabanete cv. Vermelho gigante, submetido a reposições hídricas e fertirrigação com fontes de nitrogênio. In: INOVAGRI INTERNATIONAL MEETING, 4., Fortaleza. Anais... Fortaleza: INOVAGRI, 2017. http://dx.doi.org/10.7127/iv-inovagri-meeting2017-res2850370/

BOKHTIAR, S. M.; KARIM, A. J. M. S.; HOSSAIN, K. M.; HOSSAIN, T.; EGASHIRA, K. Response of radish to varying levels of irrigation water and fertilizer potassium on clay terrace soil of Bangladesh. 
Communications in Soil Science and Plant Analysis, v. 32, n. 17-18, p. 2979-2991, 2001.

BONELA, G. D.; SANTOS, W. P. dos; ALVES SOBRINHO, E.; GOMES, E. J. da C. Produtividade e qualidade de raízes de rabanete cultivadas sob diferentes fontes residuais de matéria orgânica. Revista Brasileira de Agropecuária Sustentável, v. 7, n. 2, p. 66-74, 2017.

BREGONCI, I. dos S.; ALMEIDA, G. D. de; BRUM, V. J.; ZINI JÚNIOR, A.; REIS, E. F. dos. Desenvolvimento do sistema radicular do rabanete em condição de estresse hídrico. IDESIA, v. 26, n. 1, p. 33-38, 2008. http://dx.doi.org/10.4067/S071834292008000 100005/

CARVALHO, I, R.; KORCELSK, C.; PELISSARI, G.; HANUS, A, D.; ROSA, G, M. da. Demanda hídrica das culturas de interesse agronômico. Enciclopédia Biosfera, v. 9, n. 17, p. 969-985, 2013.

COSTA, R. N. T.; VASCONCELOS, J. P.; SILVA, L. A.; NESS, R. L. L. Interferência do excesso de água no solo e componentes de produção em beterraba. Horticultura Brasileira, v. 26, n. 1, p. 74-77, 2008. http://dx.doi.org/10.1590/S010205362008000 100014/

CUNHA, F. F.; CASTRO, M, A.; GODOY, A, R.; MAGALHÃES F, F.; LEAL, A, J, F. Irrigação de cultivares de rabanete em diferentes épocas de cultivo no nordeste sulmato-grossense. Irriga, v. 22, n. 3, p. 530546 ,

2017.https://doi.org/10.15809/irriga.2017v22n 3p530-546/

FARIA, L. M. V. de; GOMES, M. B.; SILVA, T. R. da. Resposta morfológica do rabanete à aplicação de diferentes doses de silício na linha de semeadura. Revista Eletrônica da Univar, v. 2, n. 10, p. 121-128, 2013.

FILGUEIRA, F. A. R. Novo manual de olericultura: agrotecnologia moderna na produção e comercialização de hortaliças. 3. ed. Viçosa, MG: Ed. UFV, 2008. p. 294-295.

GADUM, J.; SEABRA JÚNIOR, S.; OLIVEIRA, A. K. M.; DORNAS, M. F. Produção e qualidade de cinco cultivares de rabanete em Campo Grande-MS. In: CONGRESSO BRASILEIRO DE OLERICULTURA, 45, 2005, Fortaleza. Anais... Vitória da Conquista: Editora $\mathrm{ABH}$, 2005. 1 CD-ROM.

GRANADA, G. L.; VENDRUSCOLO, J. L.; TREPTOW, R. O. Caracterização química e sensorial de sucos clarificados de amora-preta (Rubus spp. L). Revista Brasileira de Agrociência, v. 7, n. 2, p.143-147, 2001.

GUERRA, A. M. N. de M.; FERREIRA, J. B. A.; VIEIRA, T. S.; FRANCO, J. R. Desempenho agronômico e atividade fotossintética de rabanetes nas condições amazônicas, Revista Brasileira de Agropecuária Sustentável, v. 7, n. 3, p. 2431, 2017.

KARMELI, D.; KELLER, J. Trickle irrigation design. Rain Bird Sprinkler Manufacturing Corporation, 1975. 133 p.

LIMA, E. M. de C.; MALLER, A.; HARA, A. T.; REZENDE, F. C.; CARVALHO, J. A. Efeito de diferentes níveis de água no solo na produção do rabanete cultivado em dois tipos de ambientes protegidos. Engenharia na agricultura, v. 23, n. 4, p. 346-354, 2015. https://doi.org/10.13083/reveng.v23i4.577

MARQUES, P. A. A.; SANTOS, A. C. P. Efeito de diferentes níveis de irrigação baseadas em frações do tanque classe sobre a produção de rabanete (Raphanus sativus L.). Colloquium Agrariae, v. 1, n. 2, p. 23-27, 2005.

MINAMI, K.; TESSARIOLI NETTO, J. Rabanete: Cultura rápida, para temperaturas amenas e solos areno-argilosos. Piracicaba: ESALQ - Divisão de Biblioteca e Documentação, 1997. 27 p. (Série Produtor 


\section{PRODUÇÃO DE RABANETE SOB DIFERENTES MANEJOS DE IRRIGAÇ̃̃O}

Rural, 4).

OLIVEIRA, F. R. A. de; OLIVEIRA, F. de A. de; MEDEIROS, J. F.; SOUSA, V. de F. L. de; FREIRE, A. G. Interação entre salinidade e fósforo na cultura do rabanete. Revista Ciência Agronômica, v. 41, n. 4, p. 519-526, 2010.

PEREIRA, A. J.; BLANK, A. F.; SOUZA, R. J.; OLIVEIRA, P. M.; LIMA, L. A. Efeito dos níveis de reposição e freqüência de irrigação sobre a produção e qualidade do rabanete. Revista Brasileira de Engenharia Agrícola e Ambiental, v. 3, n. 1, p. 117-120, 1999.

PULITI, J. P. M.; REIS, H. B.; PAULINO, H. D. M.; RIBEIRO, T. C. M.; TEIXEIRA, M. Z.; CHAVES, A. S.; RIBEIRO, B. R.; MACIEIRA, G. A. A.; YURI, J. E. Comportamento da cultura do rabanete em função de fontes e doses de cálcio. Horticultura Brasileira, v. 27, n. 2, p. 30033008, 2009.

REBEQUI, A. M.; CAVALCANTE, L. F.; NUNES, J. C.; DINIZ, A. A.; BREHM, M. A. da S.; BECKMANN-CAVALCANTE, M. Z. Produção de mudas de limão cravo em substrato com biofertilizante bovino irrigado com águas salinas. Revista de Ciências Agrárias, v. 32, n. 2, p. 219-228, 2009.

RODRIGUES, R. R.; PIZETTA, S. C.; TEIXEIRA, A. das G.; REIS, E. F. dos; HOTT, M. de O. Produção de rabanete em diferentes disponibilidades de água no solo. Enciclopédia Biosfera, v. 9, n. 17, p. 21212130, 2013.

SANTOS, J. C. C. dos; SILVA, C. H. da; SANTOS, C. S. dos; SILVA, C. de S.; MELO, E. B.; BARROS, A. C. Análise de crescimento e evapotranspiração da cultura do rabanete submetido a diferentes lâminas de água. Revista Verde de Agroecologia e Desenvolvimento Sustentável, v. 9, n. 1, p. 151-156, 2014.
OLIVEIRA, F de A. de; TARGINO, I. S. de O.; SILVA, M. L. do N. Tolerância do rabanete ao encharcamento do solo. Revista Verde de Agroecologia e Desenvolvimento Sustentável, v. 7, n. 1, p. 25-33, 2012.

EMPRESA BRASILEIRA DE PESQUISA AGROPECUÁRIA (EMBRAPA). Sistema Brasileiro de Classificação de Solos. 5. ed. rev. e ampl. Brasília, DF: Embrapa, 2018. 356 p.

SLOMP, J. J.; LEITE, J. A. O.; TRENTIN, A.; LEDESMA, G. S.; CECCHIN, D. Efeito de diferentes níveis de irrigação baseados em frações do tanque classe "A" sobre a produção de rabanete (Raphanus sativus L.) variedade Crimson Giant. Perspectiva, Erechim. v. 35, n. 131, p. 99-107, 2011.

VIEIRA, E. L.; SOUZA, G. S. de; SANTOS, A. R. dos; SILVA, J. dos S. Manual de fisiologia vegetal. São Luis: EDUFMA, 2010, $230 \mathrm{p}$.

SILVA, R. T. da; SOUZA, A. A. T. da; 